\title{
State-of-the-art of spatial arch bridges
}

1 Marta Sarmiento-Comesías MEng, MCICCP PhD candidate, Technical University of Catalonia (UPC), Barcelona Spain

2. Ana M. Ruiz-Teran MEng, PhD, CEng, MICE, FHEA

Lecturer in bridge engineering, Department of Civil and Environmental Engineering, Imperial College London, UK
3 Ángel C. Aparicio MEng, PhD, MCICCP Professor in bridge engineering, Technical University of Catalonia (UPC), Barcelona, Spain
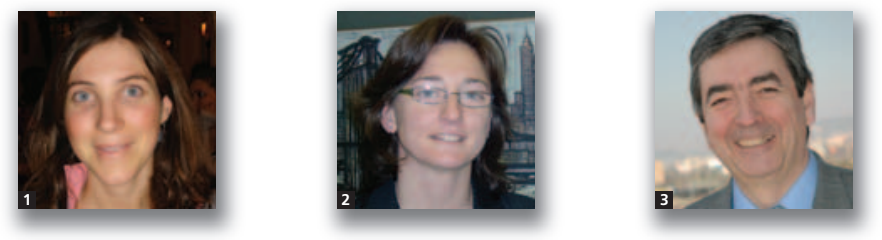

The paper describes a new form of bridge called a spatial arch bridge. This bridge type was developed in response to the demand for landmark structures, which have started to appear in the modern urban landscape to provide a symbol of originality, innovation and progress. Spatial arch bridges are defined as bridges in which the vertical deck loads produce bending moments and shear forces not contained in the arch plane, owing to their geometrical and structural configuration. Moreover, the arch itself may not be contained in a plane. The different variables and geometries that create such a structural configuration have been studied and classified. A wide compilation of examples of this bridge type has been made in chronological order, according to their construction date, from Maillart's first concrete spatial arch bridges to the latest designs and materials.

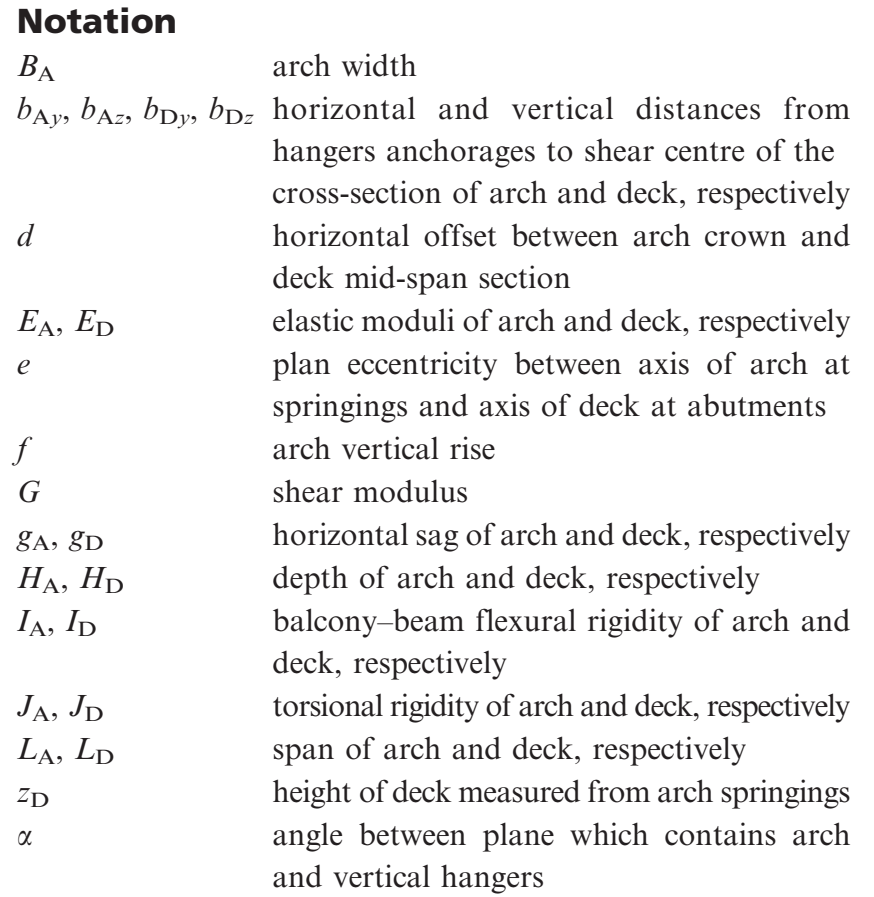

$\theta$

$\omega$

\section{Introduction}

Bridges in urban areas have in recent times acquired a new function. In addition to simply providing a physical connection between two points, they are also expected to create a landmark, as a symbol of originality, innovation and progress.

Spatial arch bridges (SABs) have appeared in response to this social demand. SABs are defined (Sarmiento-Comesías, 2009; Sarmiento-Comesías et al., 2010) as bridges in which vertical deck loads produce bending moments and shear forces not contained in the arch plane due to their geometrical and structural configuration. Moreover, the arch itself may not be contained in a plane.

New geometries for bridges have been devised: arches wind, twist and incline; cables are no longer mere structural elements 
but have become architectural features suggesting ruled surfaces which frame the space; and the asymmetry, structurally astounding, finally overcomes the structure, creating in its place a piece of sculpture (see Figure 1).

All of this is possible owing to current technological development. Faster computers enable close-to-reality simulations and highly complicated analysis. New computer-aided design/ computer-aided manufacture (CAD/CAM) technologies make buildable shapes that would otherwise be impossible to manufacture. These developments have broadened the design possibilities. However, the architectural and engineering characteristics must be in harmony in order to optimise the possibilities offered by both the new materials, and the drawing, calculation and construction methods.

However, the development of these new structural forms has not been underpinned by research. Few studies have been carried out so far on spatial bridges (Jorquera, 2007, 2009; Sarmiento-Comesías, 2009, 2010; Sarmiento-Comesías et al., 2010; 2011a, b). After six international conferences on arch

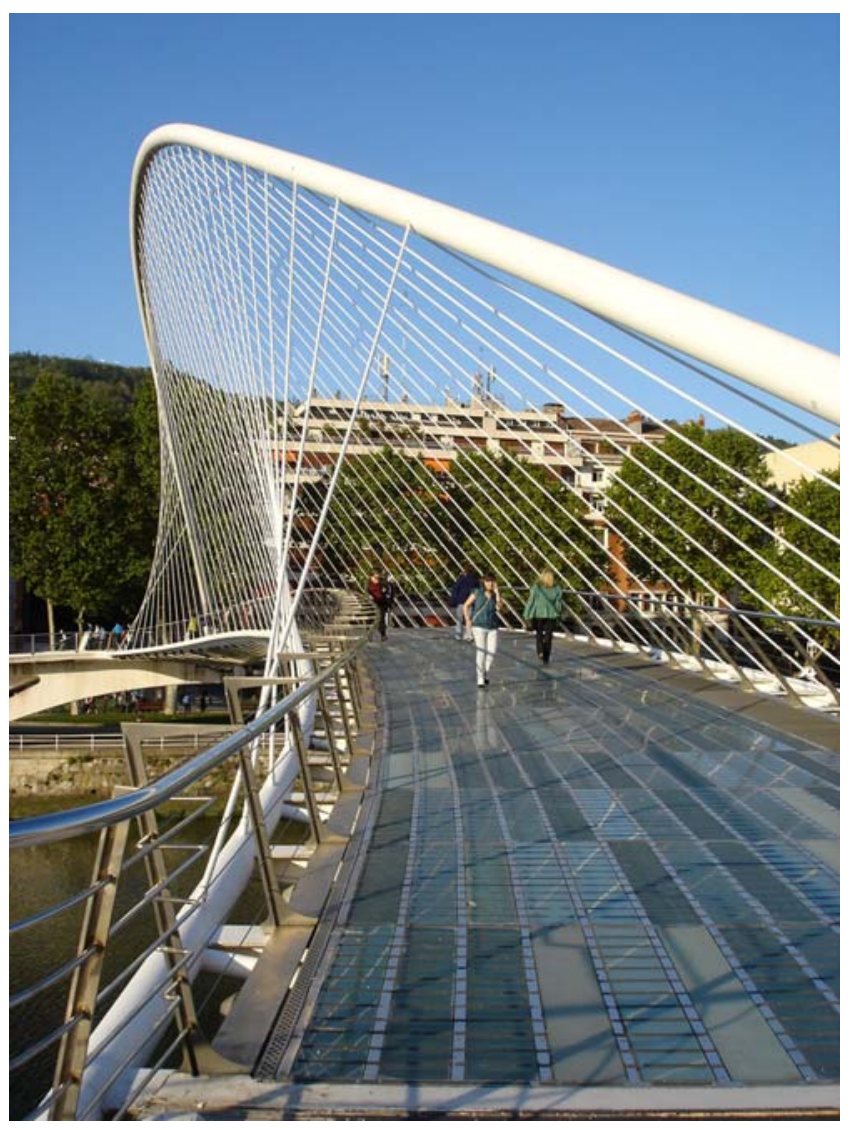

Figure 1. Campo de Volantín footbridge, Bilbao, Spain bridges, this bridge type has still not been considered, and only some examples have been presented. A deeper study is needed in order to clarify their behaviour and stability, to broaden and optimise the design possibilities and to establish design criteria. Before such a study is undertaken, it is essential to define this bridge type clearly and review the state of the art, including the research studies and some of the examples that have been completed.

\section{Objectives}

The objectives of this paper are to

define what we understand by SABs

establish the different variables involved

provide a classification for the different types of SAB

summarise the present knowledge of this bridge type, giving a brief review on how the different examples have emerged

- explain the basic principles of behaviour and point out the research studies that have been carried out so far.

\section{Definitions}

Spatial arch bridges comprise both bridges supported by arch ribs and shells. The previously given definition applies to SABs employing arch ribs. Their definition can be developed further: 'true spatial arch rib bridges' are those in which vertical deck loads centred on the deck induce internal forces not contained in the arch plane, owing to their geometrical and structural configuration. From a geometrical standpoint, arch bridges which are longitudinally asymmetrical in plan are always true SABs (see Figure 4 later in Section 4.2).

Non-true SABs are those arch bridges which are longitudinally symmetrical in plan (and therefore the arch and deck have a symmetrical cross-section) with more than one deck (e.g. see Figure 5(a) later in Section 4.2), more than one arch (inclined non-braced arches such as in the examples shown in Figure 5(b) in Section 4.2) or more than one family of hangers/struts (e.g. the arch bridge across high-speed road R52 near Bratcic (Stráský and Husty, 1997)). The spatial behaviour of non-true SABs is only activated by the eccentricity of the vertical loads on the deck or the self-weight of the inclined arches.

Classical planar vertical arch bridges which have a spatial behaviour under wind loads are not considered to be SABs. Neither are those vertical planar arch bridges with a straight deck and one centred family of vertical rigid struts or hangers that introduce horizontal shear forces in the arch under eccentric vertical loads on deck.

Shell arch bridges have a completely different configuration and structural behaviour. In such bridges the main bearing element is an arch consisting of a shell with double curvature. 


\section{Spatial arch bridge types}

Many variables are involved in the definition of a SAB. As a consequence of this, it is difficult to classify this bridge type because several criteria could be used.

Most SABs are footbridges in which either an aesthetical challenge is pursued or a curved deck is required owing to accessibility criteria. For short and medium spans, arch bridges may be justified for aesthetical, environmental or clearance reasons, as the best alternative, allowing a potential SAB solution. For larger spans, under $600 \mathrm{~m}$, arches compete with cable-stayed and suspension bridges.

Most SABs have been built with steel and composite (steel and concrete) sections. The second most employed material is structural concrete. In some particular cases other materials have been used. Stainless steel was employed in the York Millenium bridge, UK, in 2001 (Firth, 2002), the Celtic Gateway bridge in Holyhead Town, UK, in 2005 and the stainless steel-GFRP pedestrian bridge in Sant Fruitós, Spain, in 2009. The Leonardo da Vinci bridge in Aas, Norway, was built in 2001 with timber (glulam curved beams) (von Buelow et al., 2010). Ultra-high performance concrete has also been used in the case of a research study for shell arch bridges (Strasky, 2008; Terzijski, 2008).

\subsection{Definition of variables}

There is a high number of variables and these may be combined in many different ways. However, not all the combinations are structurally or geometrically possible. In addition, for some possible combinations, no bridges have been built yet.

The different variables are defined as follows (Figure 2).

Type of arch members: ribs and shells.

Geometrical shape

- number of arches, decks, and sets of hangers (when the deck is beneath the arch) or struts (when the deck is over the arch)

- number of elements (hangers and/or struts) per set and spacing between them

- arch and deck spans ( $L_{\mathrm{A}}$ and $L_{\mathrm{D}}$ respectively), horizontal arch and deck sags ( $g_{\mathrm{A}}$ and $g_{\mathrm{D}}$ respectively), arch rise $\left(f_{\mathrm{A}}\right)$, geometric shape of the arch

- angular tilt of the arch from the vertical plane $(\omega)$

- relative position between the arch and deck.

- In elevation: it can be determined by the position of the deck in relation to the arch; the definition can be based on a relationship between the arch rise $f_{\mathrm{A}}$ and the height of the deck measured from the arch springings $z_{\mathrm{D}}$ (Figure 2(c)). The bridge can have an 'inferior deck' $\left(z_{\mathrm{D}}=0\right.$, i.e. a bridge with a spatial

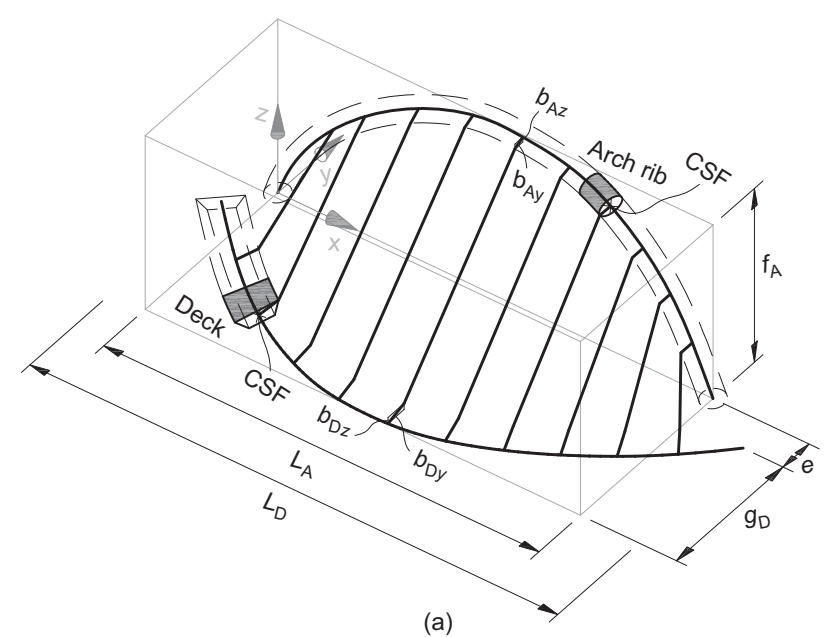

(a)

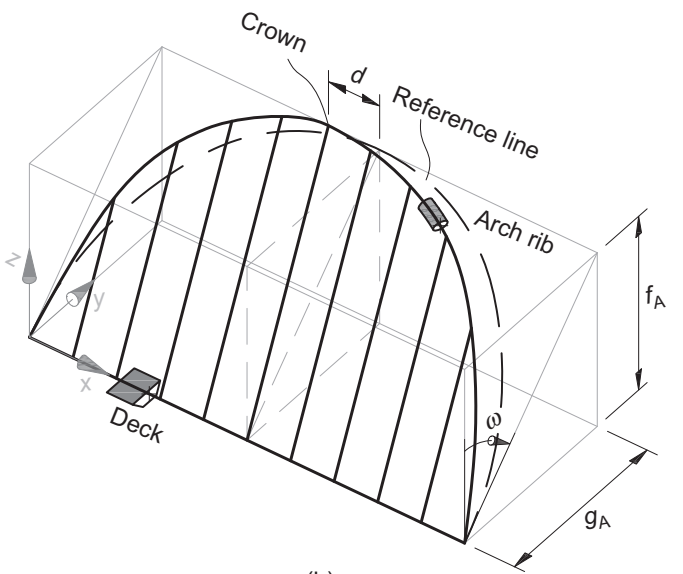

(b)

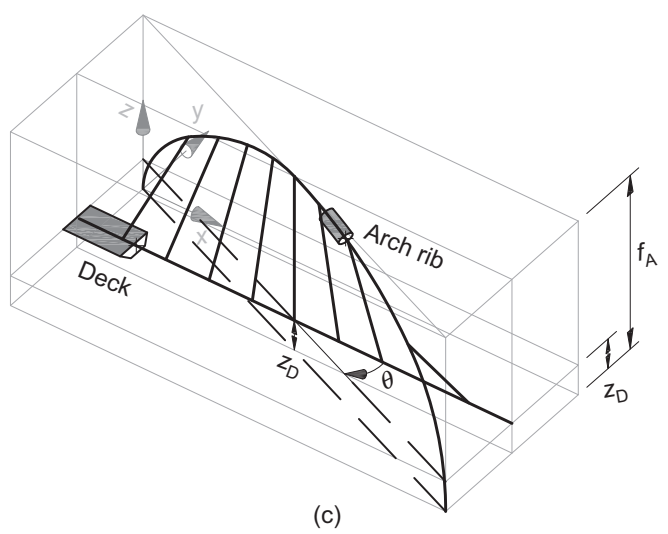

Figure 2. Definition of relevant variables: (a) vertical arch with a curved inferior deck; (b) inclined arch with a straight inferior deck; (c) rotated arch with intermediate deck

arch over the deck), a 'superior deck' $\left(z_{\mathrm{D}} \geqslant f_{\mathrm{A}}\right.$, i.e. a bridge with a spatial arch under the deck) or an 'intermediate deck' $\left(0<z_{\mathrm{D}}<f_{\mathrm{A}}\right.$, i.e. a bridge with a spatial arch beneath and above the deck). For these 
definitions, inferior, superior and intermediate only have a geometrical meaning, related to the position of the deck in relation to the arch.

- Plan eccentricity between the arch springings and the deck abutments $(e)$.

- Horizontal offset between the arch crown and the deck mid-span section $(d)$.

- Rotation of the arch in plan in relation to the alignment of the deck $(\theta)$.

Material.

- Support conditions for both the arch and the deck at the abutments.

Deck-supporting members (hangers and struts)

- slope of the deck-supporting members (with or without a network configuration)

- distances from either the hanger anchorages or the strut connections to the shear centre of the cross-section of the arch ( $b_{\mathrm{A} y}$ horizontallly and $b_{\mathrm{A} z}$ vertically) and the deck ( $b_{\mathrm{D} y}$ horizontally and $b_{\mathrm{D} z}$ vertically)

- flexural stiffness of the deck-supporting members: rigid (mainly, either steel profiles for inferior-deck SAB or steel or concrete members for superior-deck $\mathrm{SAB}$ ) or flexible (mainly stays and cables for inferior-deck SAB) members

- the prestressing of the deck-supporting members: active (mainly post-tensioned hangers) or passive (non-prestressed) members.

Geometrical variables are a clear way of classifying bridges. Nevertheless, from a structural standpoint, either geometrical or mechanical dimensionless ratios are more appropriate, as several studies attest (Jorquera, 2007; Sarmiento-Comesías, 2009).

Geometrical ratios

n ratio between the distance from the deck shear centre to the axis joining the deck abutments and the span of the deck: $\left(g_{\mathrm{D}} \pm b_{\mathrm{D} y}\right) / L_{\mathrm{D}}$; similarly for the arch: $\left(g_{\mathrm{A}} \pm e \pm\right.$ $\left.b_{\mathrm{A} y}\right) / L_{\mathrm{A}}$

- ratio between the arch depth and width $\left(H_{\mathrm{A}} / B_{\mathrm{A}}\right)$; this coefficient is required because of the relevance of the out-of-plane behaviour of the arch

- the deck/span ratio: $H_{\mathrm{A}} / L_{\mathrm{A}} ; H_{\mathrm{D}} / L_{\mathrm{D}}$

an appropriate relationship between $f_{\mathrm{A}}, e, g_{\mathrm{D}}$ and $g_{\mathrm{A}}$ might be relevant for defining the spatial shape of the arch thrust line (i.e. the anti-funicular shape of the spatial arch).

Mechanical ratios

arch/deck flexural rigidity ratio: $\left(E_{\mathrm{A}} \cdot I_{\mathrm{A}}\right) /\left(E_{\mathrm{D}} \cdot I_{\mathrm{D}}\right)$

- flexural and torsional rigidity ratio (for both the arch and the deck): $(E \cdot I) /(G \cdot J)$.

\subsection{Classification and examples}

Many types of classification can be made, owing to the high number of variables. Some variables defined in Section 4.1 appear also in classical vertical arches contained in a plane. Therefore, an interesting classification would be one that considers the variables intrinsic to SABs. Moreover, the classification criteria may either be morphological or structural. Morphological criteria will also lead to a good structural classification and they are visually clear.

A scheme of a possible classification of SABs is shown in Figure 3. A set of different levels is considered. The levels in the flowchart have been numbered from 1 to 5 in order to avoid repetitions of the same information in the different branches.

First, SABs can be divided into two large groups.

- Spatial arch ribs (Figures 4 and 5): arches in which the cross-section of the arch has a width/span and depth/span ratios low enough for the arch to be accurately analysed with frame elements with 6 degrees of freedom per node.

- Shell arches (Figure 6): arches in which the cross-section of the arch has a width/depth and width/span ratios large enough for requiring an analysis with shell elements. The arch is a roof-like structure.

Spatial arch ribs can be classified into longitudinally asymmetrical (Figure 4) and symmetrical arches (Figure 5), which can in turn be subclassified according to the relative vertical position between the arch and the deck (level 1), the deck curvature (level 2) and the number of arches (level 3). Finally, they are classified according to the shape of the arch and the deck and their relative position (levels 4 and 5).

Regarding spatial arch ribs, the following aspects should be clarified.

Multi-bridges: these bridges have multiple (at least three) convergent decks, each of which may be supported by, or on, an arch. The only already designed examples are tribridges, such as the Sanchinarro shopping mall access bridge by J. J. Arenas in Madrid (Arenas de Pablo, 2005) or the project of the Hacking Ferry bridge, also called Ribble Way, by Wilkinson Eyre, in Lancashire (Firth and Kassabian, 2001).

- Planar arches: these arches are contained in a vertical or inclined plane. This geometrical configuration allows the direct projection of the internal forces into two orthogonal planes, when employing arch cross-sections symmetrical on the arch plane.

Non-planar arches: these are not contained in a plane. Even if a circular arch cross-section is employed, internal forces 


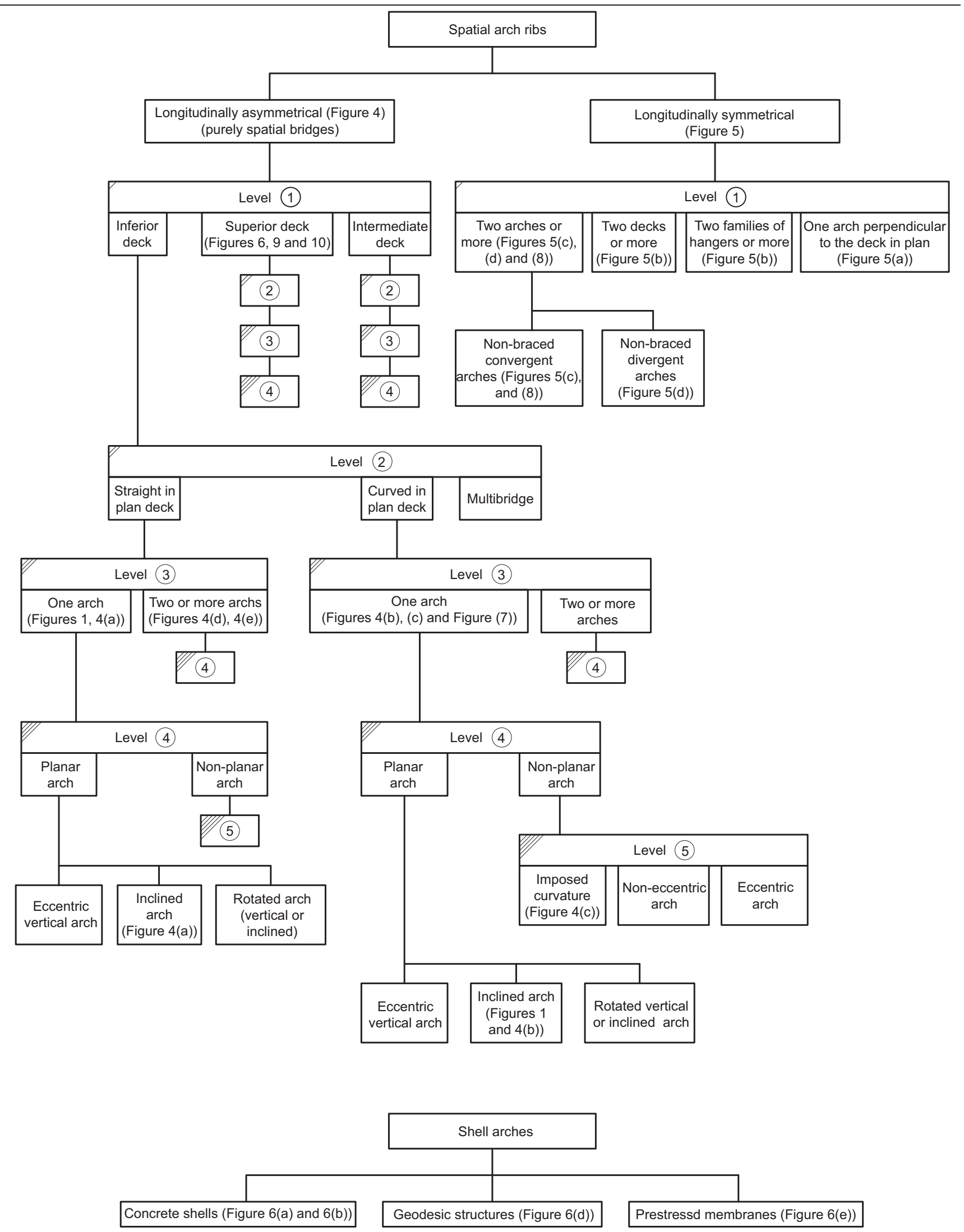

Figure 3. Classification flowchart for spatial arch bridges 


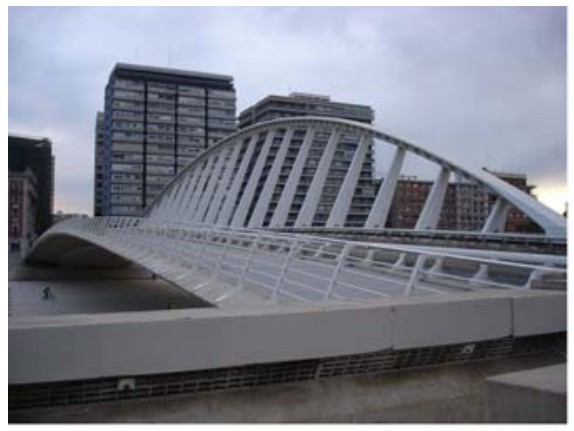

(a)

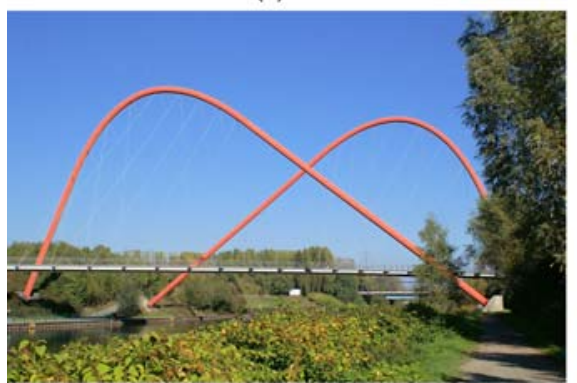

(d)

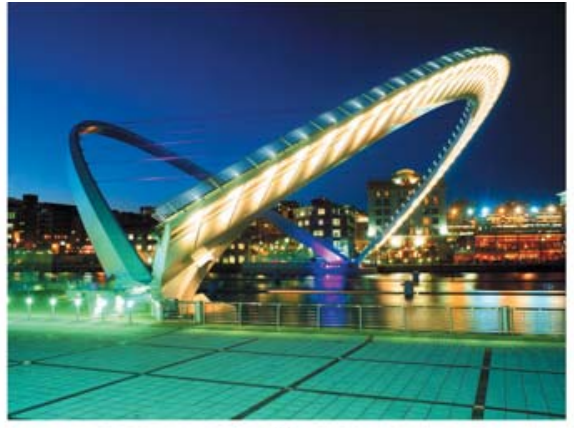

(b)

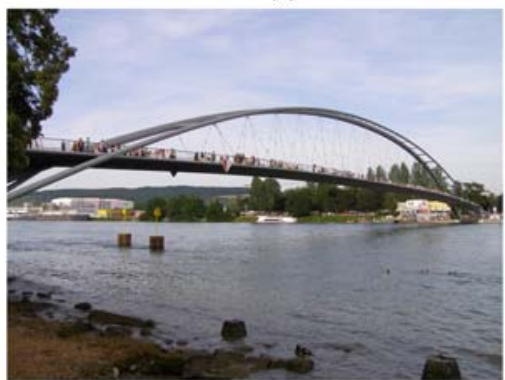

(e)

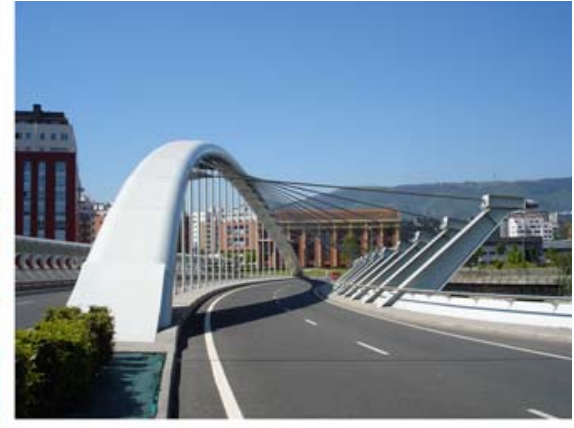

(c)
Figure 4. Longitudinally asymmetrical inferior deck spatial arch bridges: (a) inclined planar eccentric arch with straight deck, La Alameda bridge; (b) inclined planar arch with curved deck, Gateshead Millenium bridge (source: Gifford; reproduced by kind permission of Nolan Mills); (c) IDABWIC: Galindo bridge; (d) multiple-arch bridge with displaced arch crown and rotated arches, Nordsternpark double arch bridge (source: Nicolas Janberg; reproduced by kind permission of the author); (e) multiple-arch bridge with convergent braced arches, Dreiländer bridge (reproduced by kind permission of Hans-Peter Andrä) cannot be projected into two planes because internal forces are coupled.

- Arch bridges with imposed curvature (ABWICs). In these SABs, the arches are forced to have the same curvature in plan as the deck. Therefore, the arch and deck centroid lines are contained in the same vertical cylinder. They can have an inferior deck (IDABWIC) or a superior deck

(SDABWIC). In IDABWIC, the deck is located under the arch and supported by vertical hangers which do not restrict the vertical clearance (Jorquera, 2007). ABWICs can have either planar (inclined arch) or non-planar (SarmientoComesías et al., 2010) arches. Only a few bridges of this type have been built so far (see Section 5).

- Arch bridges longitudinally symmetrical in plan with two or more braced arches do not have a spatial behaviour under vertical loads, whereas asymmetrical ones can be braced without losing the spatial behaviour that characterises SABs.

- Longitudinally symmetrical bridges with one arch perpendicular to the deck in plan: this takes place in the limit of an asymmetrical bridge with a rotated arch in plan in relation to the deck alignment. When it becomes symmetrical, with $\theta \approx 90$, it should not be considered an arch bridge, but a cable-stayed bridge with an arch-shaped pylon.

Nevertheless, the arch would behave like a spatial arch (e.g. Miho Museum Bridge (Robertson, 2008)).

Not all arch bridges which look like a shell will behave like one structurally. A possible structural division is

bridges in which the arch works like a shell and supports all the bridge loads (the deck can be either inferior or superior, Figures 6(a) and 6(b)).

- spatial arch rib bridges additionally loaded with a roof shell; morphologically they look like shell arch bridges but the main loads are resisted by an arch rib

bridges in which the deck works like an arch shell (Figure 6(c))

- bridges with double-arch systems braced by a prestressed membrane acting like a roof (Figure 6(e)); this bridge type has not yet been designed but it is a very interesting option.

Very few shell arch bridges have been built so far (Corres Peiretti et al., 2010, 2011; De Lucchi, 2010; Nicoletti, 1999). Only a small number of projects and studies have been 


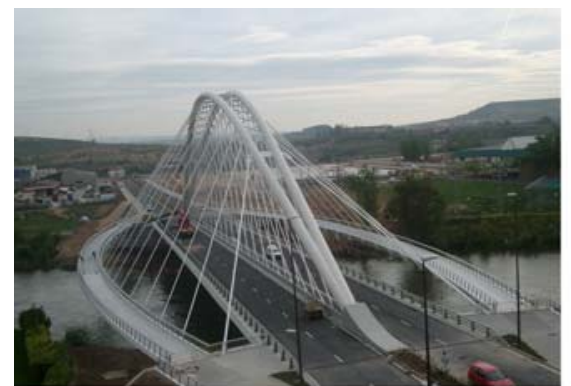

(a)

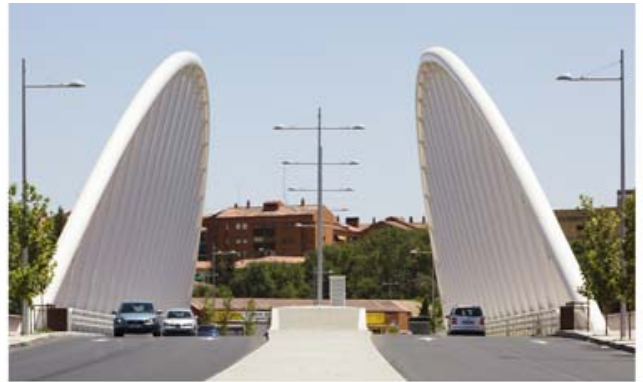

(b)

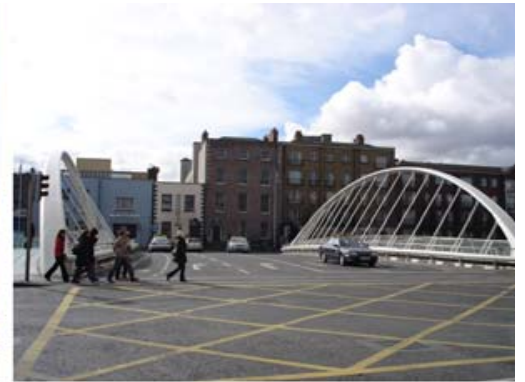

(c)
Figure 5. Longitudinally symmetrical inferior deck spatial arch bridges: (a) one-arch bridge with three decks: Logroño bridge (reproduced by kind permission of Javier Manterola); (b) multiplearch bridge with two convergent arches, Peraleda bridge (source:
AIA; reproduced by kind permission of Ramón Sánchez de León); (c) multiple-arch bridge with two divergent arches, James Joyce bridge reported (Strasky and Kalab, 2007; Strasky, 2008; Strasky et al., 2010; Terzijski, 2008).

\section{Brief historical review: examples and evolution}

Over $80 \mathrm{SABs}$ have been designed so far (Sarmiento-Comesías, 2009). In the present paper, only some representative examples of the different types, mainly the first and latest ones, are referred to.

The concept of spatiality has appeared in some masonry arch bridges, such as skew arches, succession of arches which describe an angle in plan view, and tri-bridges. In all of them, the spatial thrust line is contained in the bridge cross-section.

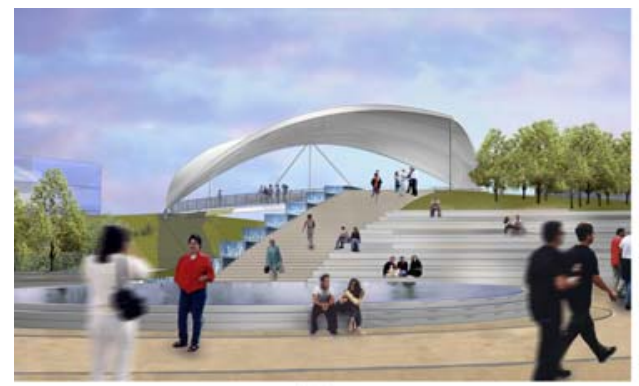

(a)

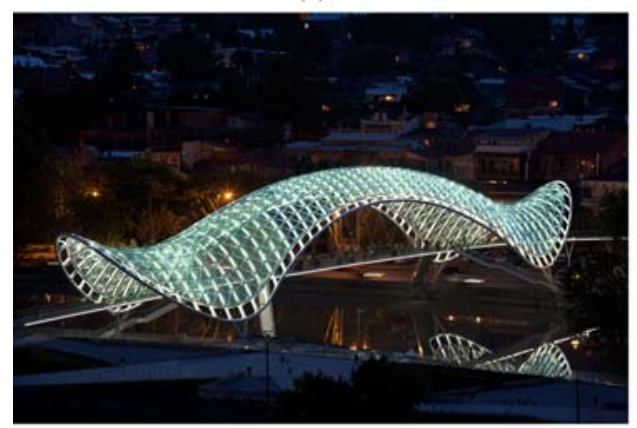

(d)

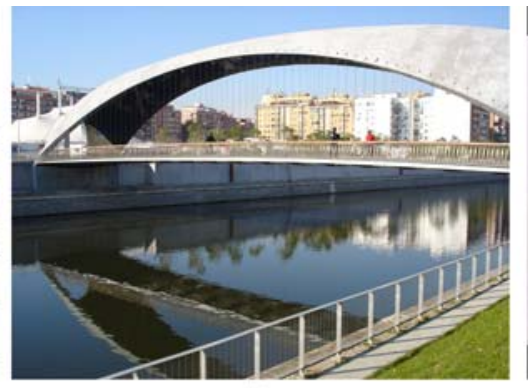

(b)

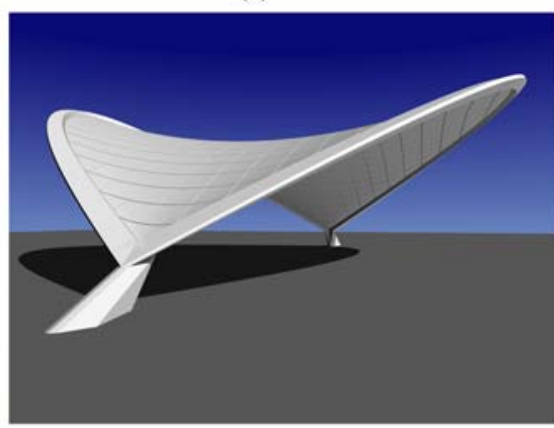

(e)
Figure 6. Shell spatial arch bridges: (a) inferior-deck shell arch bridge: project of pedestrian bridge in St Helier (reproduced by permission of Jiri Strasky and the designer, copyright Studio Bednarski Ltd); (b) inferior-deck shell arch bridge, Matadero footbridge; (c) shell arch acting as pathway, Leamouth (reproduced

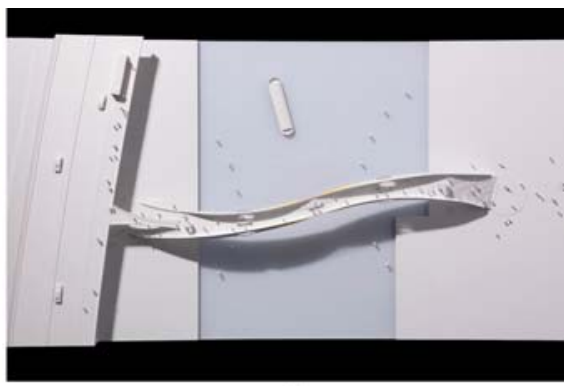

(c)

by permission of Jiri Strasky); (d) geodesic shell arch: Bridge of Peace (source: Michelle De Lucchi Archive (aMDL, 2012); photographer: Gia Chkhatarashvili; reproduced by kind permission of Michele De Lucchi); (e) studies of prestressed membranes (reproduced by permission of Jiri Strasky) 
Leonardo da Vinci in 1502 had the foresight to design more slender masonry spatial arches, as his sketches for the Golden Horn bridge attest. His clear understanding and innovative thinking, significantly ahead of his time, led to the design of a true spatial rib arch bridge. His design was eventually built in 2001, in Aas, Norway, with timber rather than stone. It is called the Leonardo da Vinci Bridge (Allied Arts Foundation, 2001). However, spatial masonry arch bridges are not included in the definition of SABs considered in this paper. Interest is focused on bridges built with materials which resist bending forces and in which live loads may cause the pressure line to fall out of the cross-section of the bridge.

The first true SABs were deck-stiffened arch concrete bridges designed by Robert Maillart (Billington, 1997), a pioneer of this bridge type. The Ziggenbach bridge was the first to be completed in 1924 in the central east side of Wägital lake in Schwyz, Switzerland (Billington, 1997). It comprises a straightin-plan concrete arch bridge and a curved-in-plan superior deck. The demolished Landquart rail bridge also belongs to the same bridge type (Billington, 1979). The Bohlbach bridge (1932, Figure 7(a)) was the first one to have an arch with an axis curved in plan (Billington, 1997), whereas the Schwandbach bridge (1933, Figure 7(b)) was the first with an imposed curvature.

It took over 30 years for the first shell arch bridge to appear. In 1969, Sergio Musmeci built what is believed to be the first and only concrete shell arch bridge with a superior deck. It is

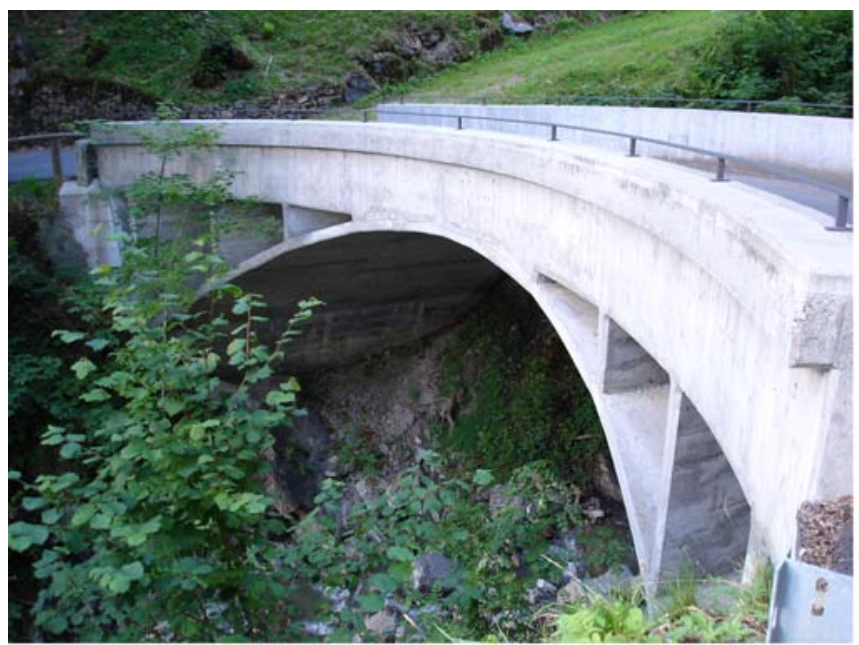

(a)

Figure 7. (a) Spatial non-planar arch bridge with a curved-in-plan superior deck, Bohlbach bridge; (b) SDABWIC, Schwandwach bridge located in Potenza, Italy, and crosses the Basento river (Nicoletti, 1999).

In 1987 the construction of the Felipe II or Bac de Roda bridge, in Barcelona, Spain, which was designed by Santiago Calatrava (Figure 8), was completed. It is the first symmetrical double-arch non-true SAB. This bridge comprises two nonbraced sets of arches, which are themselves asymmetrical braced double arches. Calatrava has designed the highest number of SABs since his first true SAB design, the Gentil footbridge in 1987. Most of them are inclined eccentric steel arches with either a curved or straight inferior deck. Examples are the Devesa footbridge in Ripoll and the Port of Ondarroa bridge, Spain, both built in 1989; la Alameda bridge (Figure 4(a)) in Valencia, Spain, built in 1991; the Europe bridge, in Orléans, France, built in 2000 (Datry, 2001; Hoeckman, 2001); the Observatory bridge in Liège, in Belgium, built in 2002 (Verlain et al., 2001); the Volantín footbridge (Flaga and Januszkiewicz, 2011); and the recent Reggio Emilia inclined and skew arch, in Italy, built in 2006. Inclined eccentric arches with inferior deck have also been widely used by other designers (some examples are described by Firth (2001), Stráský (2005) and Arenas de Pablo (2005)).

From the late 1980s, the use of bridges as city landmarks became widespread, and more examples of this bridge type were proposed. The search for a new millennium symbol enhanced the aesthetical power of SABs and generated several examples.

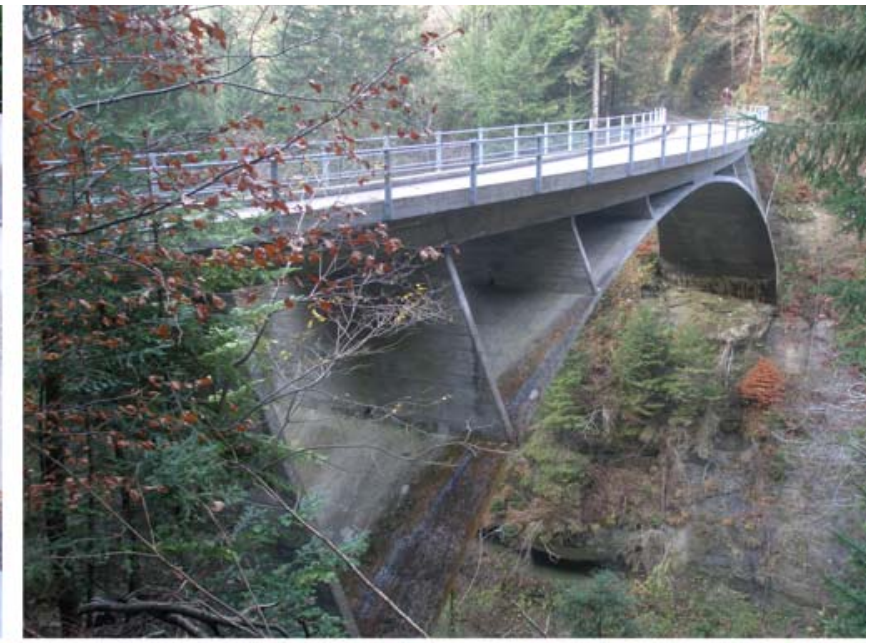

(b) 


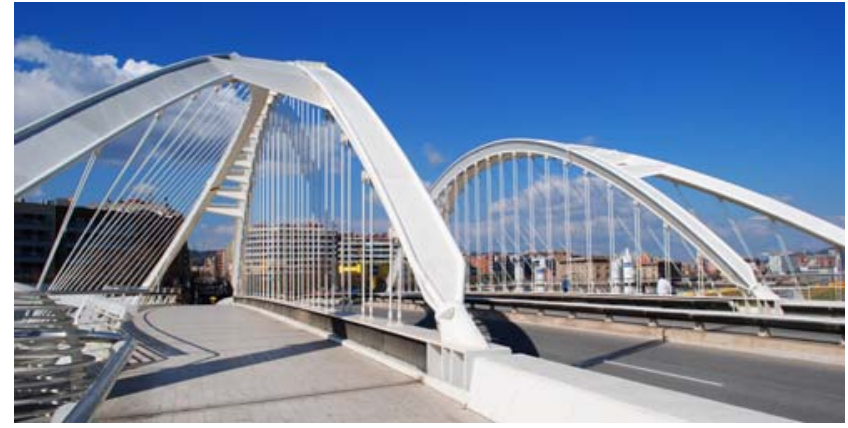

Figure 8. Bac de Roda bridge, Barcelona, Spain: a longitudinally symmetrical arch bridge with two sets of convergent non-braced arches, each of which is composed of two longitudinally asymmetrical, convergent braced arches

In the 1990s a new concept was introduced: the arch rotated in plan in relation to the deck alignment. Some examples of this type are: Nordsternpark (Figure 4(d)), built in 1996; the TZU footbridge, built in 1997; the Hulme arch bridge, built in 1997, which has become a symbol of Manchester (Hussain and Wilson, 1999); the Charvaux footbridge, and the impressive multiple-arch Juscelino Kubitschek bridge (Almeida et al., 2003), both built in 2002; and the more recent Te Rewa Rewa bridge, in New Plymouth, built in 2010.

In 1998, the construction of the Gateshead Millennium bridge over the Tyne was completed. It is the first and only spatial arch movable bridge (Figure 4(b), Butterworth et al., 2003; Curran, 2003; Johnson and Curran, 2003). One year later, the Ripshorst bridge (Figure 9) was completed (Schlaich and

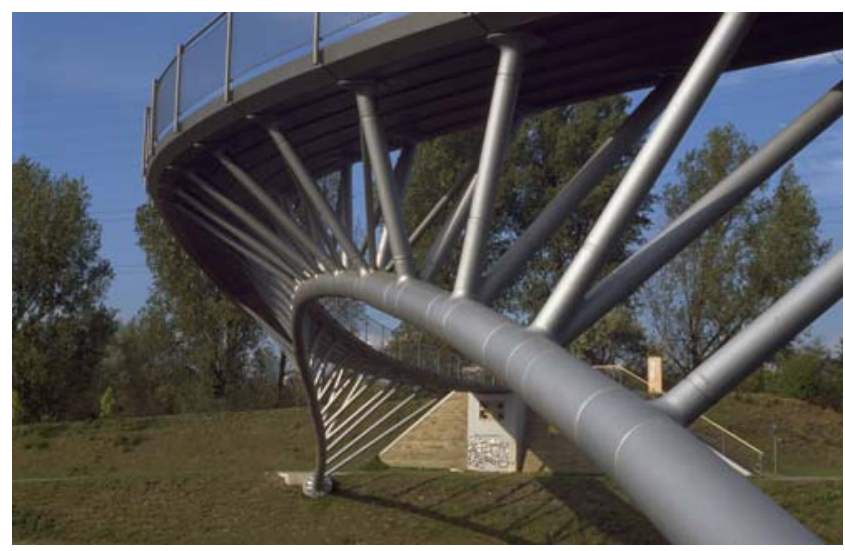

Figure 9. Ripshorst bridge: spatial non-planar, anti-funicular arch bridge with a curved superior deck (reproduced by kind permission of Mike Schlaich. Copyright: Schlaich, Bergermann und Partner)
Moschner, 1999). It has a non-planar and anti-funicular arch (i.e. an arch in which the thrust line follows the arch centroid line, and therefore the arch works mainly under compression for a certain loading condition).

In the same period, the first divergent arches were employed: St James Garden footbridge in London, 1995; Butterfly bridge in Bedford, 1998 or Friends bridge in London, 1998. More recent examples include the Churchill way footbridge in Hampshire, 2000-2003; the James Joyce bridge in Dublin, 2003 (Figure 5(c)); and the Ponte della Musica in Rome, 2011 (Liaghat et al., 2011). There are fewer examples of asymmetrical divergent arches, such as the Celtic Gateway bridge in Wales, 2003-2005, and the anti-funicular Nanning Butterfly tied-arch bridge in Guangxi, 2009 (Cheng et al., 2010).

Some examples of symmetrical arch bridges with several decks are the bridge over the Guadalentín River in Lorca, Spain, 2002 (Manterola et al., 2005) and the Father Bernatek's footbridge over the River Vistula in Cracow, Poland, 2010 (Flaga and Januszkiewicz, 2011), both with two decks, and the Logroño bridge (Figure 5(a)), Spain, 2003, with three decks (Manterola, 2001).

The structural schemes conceived by Maillart for his deckstiffened SABs with imposed curvature were not subsequently used until Manterola designed the Endarlatsa (Figure 10) and the Contreras bridges. Manterola contributed to the development of this structural type, extrapolating Maillart's scheme from superior- to inferior-deck arch bridges. The bridge over the Galindo River, in Bilbao (Figure 4(c)), Spain

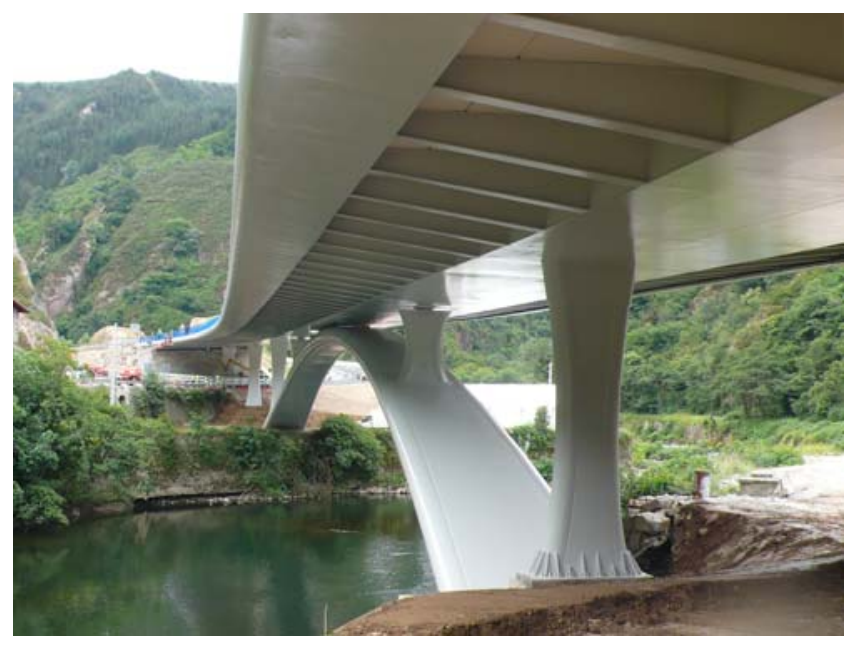

Figure 10. Endarlatsa bridge: SDABWIC (reproduced by permission of Javier Manterola) 
(Manterola et al., 2009, 2011), is the first inferior-deck SAB with imposed curvature, in which the arch has a double hanger system.

Musmeci's shell arch superior-deck bridge has still not found a successor. Nevertheless, several studies, models and designs of shell arch bridges have been developed by Strasky (Figures 6(a), 6(c), and 6(d)), although they have not yet been built (Strasky and Kalab, 2007; Strasky, 2008; Strasky et al., 2010). Matadero and Invernadero footbridges (Figure 6(b)) are the first built shell arch bridges with an inferior deck (Corres Peiretti et al., 2010, 2011). In 2010 the first geodesic shell arch bridge, the Bridge of Peace (Figure 6(d)), was built in Tbilisi, Georgia (De Lucchi, 2010).

A great range of ideas and combinations of variables is still to be discovered, designed and constructed.

\section{Recent studies on the structural behaviour of SABs}

There are very few research studies on the behaviour of this bridge type. A broad state-of-the-art review has been carried out, including the six international conferences on arch bridges held so far (see ARCH, 1995, 1998, 2001, 2004, 2007, 2010). Several papers briefly describe the arch behaviour for specific examples, but very few tackle SABs as a bridge type. The research studies carried out so far are not wide enough to establish design criteria.

Non-linear behaviour of SABs with superior deck and imposed curvature bridges have been very briefly studied (Liaghat $e t$ al., 2011; Sarmiento-Comesías et al., 2011a; Verlain et al., 2001). The effect of temperature on these bridges has only been studied for some specific subtypes (for example the Nanning bridge by Cheng et al. (2010); and a general research study of SABs with superior decks by Sarmiento-Comesías et al. (2011b)). The recent analysis methods to obtain anti-funicular arches for SABs do not converge for some cases (Jorquera, 2007) and several variables still need to be studied. Many other form-finding software could be applied, for example employing graphic statics with a CAD software together with a parametric modelling plug-in and genetic algorithms (Lachauer et al., 2011). However, this approach neglects the material stiffness, the structural deformation and the potential structural instability (buckling).

Jorquera (2007) conducted the first comprehensive research study of this bridge type, giving a first definition, variables and classification. Jorquera's research included the study of the linear behaviour of vertical planar arches with active flexible hangers and an inferior-deck SAB with different deck curvatures. He also examined the effect of the arch/deck eccentricity in plan for a given curvature. For straight decks, he studied the behaviour of the arch when varying its inclination. The effect of hanger eccentricity with respect to the shear centre of the deck is also analysed. He coded a program to obtain anti-funicular arches for inferior- and superior-deck SABs with pinned hangers. Although Jorquera carried out a wide and interesting study for different variables, his research only partly clarifies the behaviour of SABs.

After several research studies conducted by the authors (summarised in Sarmiento-Comesías (2009)), the SAB definition, variables and classification have been detailed, broadened and specified further in the present paper.

In an in-depth study of planar and non-planar IDABWIC (Sarmiento-Comesías, 2010; Sarmiento et al., 2010; SarmientoComesías et al., 2011a), both flexible and rigid hangers have been analysed, as well as different hanger/deck and hanger/arch connection types, and different cross-section combinations for arch, deck and hangers have been considered, under both symmetrical and asymmetrical vertical loading. An analytical formulation for a simplified hanger model has also been developed. This gives an intuitive point of view regarding the behaviour of this type of bridge and how it can be controlled by means of the different variables involved.

Another thorough study (Sarmiento-Comesías et al., 2011b) for different geometries of superior-deck true SABs under vertical loading and temperature variation has also been conducted, including a study of the influence of plan curvature and plan eccentricity between the arch springings and the deck abutments (variable $e$ ).

In both studies, initial considerations for tending to the antifunicular shape of arches in SAB, by combining different parameters, are presented.

Spatial arch bridges are subjected to important bending moments (as presented by specific case studies (Hussain and Wilson, 1999; Johnson and Curran, 2003)) and torsions (as presented by specific case studies (Manterola, 2001; Verlain et al., 2001)) and have low axial forces (Jorquera, 2007). This effect has been clearly demonstrated on previous studies, when the internal forces along the arch in IDABWIC were obtained for different plan curvatures, by means of modifying the values of the parameter $g$ (Sarmiento et al., 2010; SarmientoComesías et al., 2011a).

For vertical or inclined planar arches with a symmetric crosssection in relation to the arch plane, an intuitive way of understanding their behaviour is by means of uncoupling in-plane and out-of-plane behaviour. In-plane it works like an arch: axial forces and in-plane bending moments are 
coupled. Out of plane, it works as a so-called balcony beam (Sarmiento-Comesías et al., 2011a), that is a fully restrained curved beam with the loads acting perpendicular to the plane containing the beam centroid line. For the latter, the torsional moments and out-of-plane bending moments are coupled. Depending on the relevant ratios between different variables, either the arch or the balcony beam behaviour is enhanced.

When either the arch is not contained in a plane or the crosssection is not symmetrical in relation to the plane of the arch, this simple approach is no longer possible. However, it has been demonstrated for some cases that employing an inclined plane of approximation for the arch in IDABWIC is good enough in order to understand the internal forces behaviour of the arch (Sarmiento-Comesías et al., 2011a).

It can be intuitively understood that the higher either the arch plan curvature or the angle between the plane containing the arch and the hangers/struts, the higher the out-of-plane effects, that is the arch behaviour diminishes and the balcony-beam behaviour increases. It has been demonstrated that when employing mechanisms that increase the horizontal stiffness of the system, the behaviour improves (Jorquera, 2007, 2009; Laffranchi and Marti, 1997; Manterola et al., 2009; Sarmiento et al., 2010; Sarmiento-Comesías et al., 2011a).

Nevertheless, even if it is possible to separate the behaviour into two planes, the behaviour is not always obvious and predictable, because the relationship between bending and torsional rigidities, the hanger/struts connection types and eccentricities, and the support conditions of the arch and deck at the abutments, play a fundamental role in the arch behaviour (Sarmiento-Comesías et al., 2011a).

Other main conclusions of these studies can be summarised as follows.

A key geometrical parameter to control the arch behaviour is the plan eccentricity $e$ (Jorquera, 2007, 2009).

- Employing both a rigid hanger-deck system (deck with high torsional rigidity and hangers with high transverse flexural rigidity) and an arch with low flexural rigidity has proven to be more efficient to enhance the arch behaviour in IDABWIC than increasing the rigidity of the arch (Sarmiento-Comesías et al., 2011a). This is the simplest way to make the arch tend to its anti-funicular form. In addition, when the hanger-deck system is rigid enough, geometrically non-linear effects are negligible. Moreover, the critical buckling load is much higher than that of a planar vertical bridge because the arch takes lower axial forces (Sarmiento-Comesías et al., 2011a).
For IDABWIC with large $g_{\mathrm{A}} / f$ ratios, the most unfavourable live load case for the design bending moments and shear forces in the arch is obtained when the uniform distributed live loading is applied on the whole deck span, whereas for a conventional vertical arch bridge (tied arches with $g=0$ ) the maximal arch shear forces, bending moments and deflections are higher for a uniform distributed loading applied on half the deck span (Sarmiento-Comesías et al., 2011a).

When the deck is curved in plan, it is convenient to restrain longitudinal displacements of the deck abutments under both vertical loadings and temperature increments. This design criterion is completely different to that in conventional vertical arch bridges (Sarmiento-Comesías et al., 2011b). The deck plan curvature drastically reduces the axial forces caused by temperature increments with respect to a conventional arch bridge with a straight deck with the longitudinal displacements restrained at the abutments. As a result, significant bending moments about the vertical axis appear in the deck. In addition, the arch helps the deck to resist the balcony beam components of the forces. An efficiency index has been defined in order to measure the contribution of the arch and the deck to resist in-plane bending moments (Sarmiento-Comesías et al., 2011b).

In conclusion, SABs not only prove to be architecturally interesting, but also present reasonable structural behaviour when employing a geometry that enhances the arch/deck interaction and the adequate support conditions for both the deck and the arch at the abutments. Moreover, the deck curvature is advantageous in order to diminish the axial forces in the deck caused by temperature increments.

Considering the few references on the subject, the wide range of variables and the recent popularity of this bridge type, it is concluded that further research is necessary.

\section{Conclusions}

In this paper SABs have been fully defined and classified, and the variables that define both the geometrical and structural configuration have been presented.

- The SAB type has its origins in some of Maillart's bridges built at the beginning of the nineteenth century, whose rationale was based on functional considerations. Its use has reached its peak in the 1990s, becoming increasingly popular in urban areas as a means of creating city landmarks.

- In spite of the significant number of SABs built, not enough systematic research studies focused on their structural behaviour have been developed.

- Existing research studies demonstrate the relevance of the 
out-of-plane internal forces (i.e. the behaviour as balcony beam) in SABs.

The plan eccentricity between the arch springings and the deck abutments and the stiffness of the hanger-deck system are key parameters to control the arch behaviour.

- Curved decks improve the behaviour of arch bridges under temperature increments with the longitudinal displacements restrained at the deck abutments.

- Many lines of research are currently open in this field in order to clarify linear and non-linear behaviour, to establish design criteria and to optimise the bridge behaviour.

\section{Acknowledgements}

The authors would like to thank the support received by the first author from both the FPU Scholarships of the Spanish Government and the Catalan Institution of Civil Engineers.

\section{REFERENCES}

Allied Arts Foundation (2001) The Leonardo Bridge Project, see http://www.leonardobridgeproject.org/ (accessed 19/02/ 2012).

Almeida PAO, Stucchi FR, Rodrigues JFS, Wainberg M and Berger D (2003) Retroanálise dos ensaios na $3{ }^{\text {a }}$ Ponte sobre o Lago Sul de Brasília (Retronanalysis of the tests of the 3rd bridge over the South Lake in Brasilia). Proceedings of V Simpósio EPUSP sobre Estruturas de Concreto, São Paulo (in Portuguese).

aMDL (Michele De Lucchi Archive) (2012) Ponte della Pace, Tbilisi (Georgia), 2009-2010; Project: Michele De Lucchi with Alberto Bianchi, Marcello Biffi, Giorgi Khmaladze, Francesco Faccin, Giuseppe Filippini; Engineering: Favero \& Milan Ingegneria; General contractor: Permasteelisa; Stucture: Cimolai; Client: Old City Rehabilitation and Development Fund; Photo: Gia Chkhatarashvili, see http:// www.archive.amdl.it/en/index.asp (accessed 02/04/2012).

ARCH (1995) Arch Bridges: Proceedings of the 1st International Conference on Arch Bridges, Thomas Telford, Bolton, UK.

ARCH (1998) Proceedings of the 2nd International Arch Bridge Conference, Venice. Taylor \& Francis.

ARCH (2001) Proceedings of the 3rd International Arch Bridge Conference, ARCH '01, Presses de l'Ecole nationale des ponts et chaussées, Paris, 19-21 September, 1008p.

ARCH (2004) Arch Bridges IV. Advances in Assessment,

Structural Design and Construction. Proceedings of the 4th International Conference on Arch Bridges (Roca P and Molins C (eds)), CIMNE, Barcelona, Spain.

ARCH (2007) Proceedings of the 5th International Arch Bridge Conference, ARCH '07 (Lourenço PB, Oliviera D and Portela V (eds)), Multicomp, Lda Publishers, Funchal, Madeira, Portugal.

ARCH (2010) Proceedings of the 6th International Arch Bridge Conference, ARCH'10 (Baochun Chen and Jiangang Wei (eds)), College of Civil Engineering, Fuzhou University, Fuzhou, China.

Arenas de Pablo JJ (2005) Calidad en la ingeniería: inovación y madurez (Quality in engineering: innovation and maturity). In Proceedings of AEC 2005, The Life of Bridges, San Sebastián. Asociación Española de la Carretera, Madrid, Spain, p. 341 and p. 343 (in Spanish).

Billington DP (1979) The role of science in engineering. In Robert Maillart's Bridges. The Art of Engineering. Princeton University Press, Princeton, New Jersey, pp. 94 105, 111-112.

Billington DP (1997) Robert Maillart. Builder, Designer, and Artist. Cambridge University Press, Cambridge, UK, pp. 146-149, 174-182.

Butterworth K, Carr D and Kassabian P (2003) Gateshead Millenium Bridge, UK: fabrication, assembly and erection. Proceedings of the Institution of Civil Engineers - Civil Engineering 156(1): 11-19, paper 12826.

Cheng KM, Ketchum MA and Drouillard F (2010) Nanning butterfly tied arch bridge over the Yong River in China. Structural Engineering International 20(3): 308-311.

Corres Peiretti H, Seijo Veiguela C, García Espinel JD et al. (2010) Aplicación de tecnologías avanzadas del hormigón en las pasarelas en cáscara sobre el río Manzanares para el proyecto de Madrid Río. Revista Obras Públicas (ROP) 3.515: 7-18 (in Spanish).

Corres Peiretti H, Sánchez Delgado J and Sanz Manzanedo C (2011) Pasarelas cáscara sobre el río Manzanares en Madrid. Proceedings of $V$ Congreso ACHE, Barcelona (in Spanish).

Curran P (2003) Gateshead Millenium Bridge, UK. Structural Engineering International 13(4): 214-216.

Datry JB (2001) The Europe Bridge in Orléans (France): lessons learnt. Proceedings of the 3rd International Arch Bridge Conference, ARCH '01, Paris, pp. 735-743 (in French).

De Lucchi M (2010) The bridge of peace. A monument to Tbilisi's different identities. Proceedings of the 34th IABSE International Symposium on Bridge and Structural Engineering, Venice, Italy, pp. 1-8 (CD-ROM).

Firth I (2002) New materials for modern bridges. Footbridge 2002. Paris, November, pp. 174-186.

Firth IPT and Kassabian PE (2001) The Ribble Way: characteristics of a three-way arch. Proceedings of the $3 \mathrm{rd}$ International Arch Bridge Conference, ARCH '01, Paris, pp. 807-812.

Flaga K and Januszkiewicz K (2011) On the aesthetics and technical efficiency of current arched footbridges.

Proceedings of the 4th International Conference, Footbridge 2011, Wroctaw, Poland.

Hoeckman W The Europe Bridge in Orléans (France): construction phases. Proceedings of the 3rd International Arch Bridge Conference, ARCH '01, Paris, pp. 745-750. Hussain N and Wilson I (1999) The Hulme Arch Bridge, 
Manchester. Proceedings of the Institution of Civil

Engineers - Civil Engineering 132(1): 2-13.

Johnson J and Curran P (2003) Gateshead Millenium Bridge an eye-opener for engineering. Proceedings of the Institution of Civil Engineers - Civil Engineering 156(1): 16-24, paper 12885.

Jorquera JJ (2007) Study of the Structural Behaviour of Spatial Arch Bridges. PhD thesis, Technical University of Madrid (UPM), Madrid, Spain (in Spanish), see http://oa.upm.es/ 812/1/JUAN_JOSE_JORQUERA_LUCERGA.pdf (accessed 21/02/2011).

Jorquera JJ (2009) Structural behaviour of spatial arch bridges. In Proceedings of the International Association for Shell and Spatial Structures (IASS) Symposium 2009, Evolution and Trends in Design, Analysis and Construction of Shell and Spatial Structures, Valencia (Domingo A and Lázaro C (eds)). pp. 2447-2457.

Lachauer L, Jungjohann $\mathrm{H}$ and Kotnik T (2011) Interactive parametric tools for structural design. Proceedings of the 35th IABSE-IASS International Symposium on Bridge and Structural Engineering, Taller, Longer, Lighter, London, UK, pp. 1-8 (CD-ROM).

Laffranchi M and Marti P (1997) Robert's Maillart's concrete arch bridges. Journal of Structural Engineering 123(10): $1280-1286$.

Liaghat D, Powell-Williams K and Capasso M (2011) Ponte della Musica: an urban bridge in Rome. Proceedings of the 4th International Conference, Footbridge 2011, Wrocław, Poland.

Manterola J (2001) Composite arch bridges. Proceedings of the 3rd International Arch Bridge Conference, ARCH '01, Paris, pp. 779-785.

Manterola J, Muñoz-Rojas J, López A and Fernández J (2005) Actuación sobre el río Guadalentín y espacio urbano del barrio de San Cristóbal en la ciudad de Lorca (Guadalentin river and San Cristobal urban area project in the city of Lorca). Proceedings of ACHE 2005 (Comunicaciones al III congreso ACHE de puentes y estructuras), Zaragoza, pp. 1802-1811 (in Spanish).

Manterola J, Gil MÁ and Muñoz-Rojas J (2009) Arch spatial bridges over the Galindo and Bidasoa rivers. Cauce 2000: Revista de ingeniería civil 147: 20-29 (in Spanish).

Manterola J, Gil MÁ and Muñoz-Rojas J (2011) Arch spatial bridges over the Galindo and Bidasoa rivers. Structural Engineering International 21(1): 114-121.

Nicoletti M (1999) Sergio Musmeci: Organicità di Forme e Forze nello Spazio. Testo and Immagine, Torino, Italy.

Robertson L (2008) A life in structural engineering. In: Nordenson, Guy. Seven Structural Engineers: The Felix Candela Lectures (Nordenson G (ed.)). The Museum of Modern Art, New York, USA, pp. 83-84.

Sarmiento-Comesías M (2009) Non-linear Behaviour and Design Criteria for Spatial Arch Bridges. MPhil-PhD transfer internal report, Technical University of Catalonia (UPC),
Barcelona, Spain, jointly supervised by Aparicio and RuizTeran, Barcelona (in Spanish).

Sarmiento-Comesías M (2010) Hanger joint for imposed curvature arch bridges. In Non-linear Behaviour and Design Criteria for Spatial Arch Bridges. PhD thesis, Technical University of Catalonia (UPC), Barcelona, Spain, jointly supervised by Aparicio and Ruiz-Teran, Barcelona.

Sarmiento M, Ruiz-Teran AM and Aparicio AC (2010) Structural response of spatial arches with imposed curvature. Proceedings of the 34th International Symposium on Bridge and Structural Engineering, Venice, Italy, pp. 1-8 (CDROM).

Sarmiento-Comesías M, Ruiz-Teran AM and Aparicio AC (2011a) Structural behaviour of inferior-deck spatial arch bridges with imposed curvature. Journal of Bridge Engineering 10.1061/(ASCE)BE.1943-5592.0000282 (29 June 2011), n.4, v.17, July/August 2012, pp. 682-690.

Sarmiento-Comesías M, Ruiz-Teran AM and Aparicio AC (2011b) Superior deck spatial arch bridges. Proceedings of the 35th IABSE-IASS International Symposium on Bridge and Structural Engineering, Taller, Longer, Lighter, London, UK, pp. 1-8 (CD-ROM). IABSE-IASS, International Association for Bridge and Structural Engineering, Zurich, Switzerland; International Association for Shell and Spatial Structures, Madrid, Spain.

Schlaich J and Moschner T (1999) Die Ripshorster Brücke über den Rhein-Herne-Kanal, Oberhausen. Bautechnik 6(76): 459-462.

Stráský J (2005) Bridges designed by Strasky, Husty \& Partner. In Proceedings of AEC 2005, The Life of Bridges, San Sebastián. Asociación Española de la Carretera, Madrid, Spain, pp. 255-312.

Strasky J (2008) Bridges utilizing high-strength concrete. Proceedings of the 30th Conference of Slovenian Structural Engineers, Bled, pp. 1-18.

Stráský J and Husty I (1997) Arch bridge crossing the BrnoVienna expressway. Proceedings of International Conference on Composite Constructive - Conventional and Innovative, Innsbrück, pp. 870-871.

Strasky J and Kalab P (2007) Model test of the prestressed concrete membrane. Proceeding of IASS 2007 Conference on Shell and Spatial Structures, Structural Architecture Towards the Future Looking to the Past, Venice, Italy, pp. 1-8, CD-ROM.

Strasky J, Kalab P, Necas R and Terzijski I (2010) Development of membrane roofs from prestressed concrete. structural concrete in the Czech Republic 2006-2009. Proceedings of the 3rd fib Congress, Washington.

Terzijski I (2008) Optimization of UHPC for the model of a pedestrian bridge. In Ultra High Performance Concrete (UHPC), Proceedings of the 2nd International Symposium on Ultra High Performance Concrete (Fehling E, Schmidt $\mathrm{M}$ and Stürwald S (eds)). Kassel, Germany, pp. 707-716. Verlain D, Hardy D, Schmit C et al. (2001) Bowstring bridge with 
curved deck. Proceedings of the $3 r$ International Arch Bridge Conference, ARCH'01, Paris, pp. 715-722 (in French).

von Buelow P, Falk A and Turrin M (2010) Optimization of structural form using a genetic algorithm to search associative parametric geometry. Proceedings of the International Conference on Structures and Architecture (ICSA) 2010, Guimarães, Portugal.

\section{WHAT DO YOU THINK?}

To discuss this paper, please email up to 500 words to the editor at journals@ice.org.uk. Your contribution will be forwarded to the author(s) for a reply and, if considered appropriate by the editorial panel, will be published as discussion in a future issue of the journal.

Proceedings journals rely entirely on contributions sent in by civil engineering professionals, academics and students. Papers should be 2000-5000 words long (briefing papers should be 1000-2000 words long), with adequate illustrations and references. You can submit your paper online via www.icevirtuallibrary.com/content/journals, where you will also find detailed author guidelines. 